\title{
Autonomia da Vontade e aUtonomia PRIVAda no Sistema JURídico BRASILEIRO
}

\author{
Autonomy of will and private autonomy in the brazilian legal system
}

Janaína Reckziegel

Doutora em Direitos Fundamentais e Novos Direitos pela Universidade Estácio de Sá - Rio de Janeiro. Mestre em Direito Público. Especialista em Mercado de trabalho e exercício do magistério em preparação para a Magistratura e em Educação e docência no ensino superior. Graduada em Ciências Jurídicas e Sociais pela Universidade do Oeste de Santa Catarina. Professora e Pesquisadora da Universidade do Oeste de Santa Catarina (UNOESC). Editora de Seção da Revista Espaço Jurídico Journal of Law. Advogada e Professora Universitária E-mail:janaina.reck@gmail.com

\section{Roni Edson Fabro}

Mestrando em Direito Fundamentais Civis da Universidade do Oeste de Santa Catarina (UNOESC), campus Chapecó(SC). Mestre em Relações Internacionais para o MERCOSUL pela Universidade do Sul de Santa Catarina. Especialista em Direito Civil pela Universidade do Oeste de Santa Catarina. Especialista em Direito Processual Civil pela Universidade do Contestado. Graduado em Direito pela Universidade do Oeste de Santa Catarina. Professor do Curso de Direito da UNOESC campus de Joaçaba(SC). Advogado desde 1991. E-mail: roni.fabro@unoesc.edu.br

RECEBIDO EM: 09.03.2014

APROVADO EM: 07.07.2014

\section{Resumo}

O estudo trata da autonomia da vontade, a partir da Constituição Federal de 1988 e do Código Civil de 2002. Verifica-se a supremacia do texto constitucional, que trouxe à tona o princípio da dignidade da pessoa humana às relações jurídicas privadas, decorrente de alterações históricas pontuais, operadas na história do País. Com os novos tempos inaugurados a partir da promulgação do texto constitucional de 1988, valorizou-se mais a preservação do indivíduo, privilegiando-se a pessoa humana. As implicações constitucionais no Código Civil de 2002, com a aplicabilidade direta das normas constitucionais, deu origem à constitucionalização do Direito Civil, motivo pelo qual a interpretação do Código Civil deve ocorrer de acordo com a Constituição e não a Constituição segundo o Código Civil. Como a comissão reda- 
tora do atual Código Civil foi constituída em 1969, o Projeto de Lei 634 apresentado em 1975 e se tornou lei somente em 2002, com a Constituição de 1988 houve a necessidade de sua adequação aos preceitos e normas constitucionais. O entendimento da autonomia da vontade passa pelo que dispõe o art. $5^{\circ}$, II, da Constituição Federal. A autonomia da vontade se constitui no poder que a pessoa possui de estabelecer determinado negócio jurídico com alguém, objetivando a constituição de uma relação jurídica privada. É mencionada a diferença existente entre autonomia da vontade e autonomia privada ou se são institutos similares. Verifica-se que o instituto da autonomia da vontade está inserido no contexto do Direito Civil e que sua utilização, pela pessoa, na efetivação de negócios jurídicos privados, deve observar os princípios constitucionais.

Palavras-chave: Direitos fundamentais. Autonomia da vontade. Autonomia PRIVADA. DignidADE HUMANA.

\section{Abstract}

This study examines the autonomy of will in the Federal Constitution of 1988 and in the Civil Code of 2002. The supremacy of the Constitution brought out the principle of human dignity to private legal relations arising of specific historical changes in the country's history. The promulgation of the Constitution of 1988 opened a new era, preservating the individual and privileging the human person. The Civil Code of 2002 constitutional implications, with the direct application of constitutional norms, gave birth to the constitutionalization of civil law, which is why the interpretation of the Civil Code must take place according to the Constitution and not the other way around. As the writing committee of the current Civil Code was constituted in 1969, and the Bill 634 was introduced in 1975 and was approved only in 2002, with the Constitution of 1988 it was necessary to adapt principles and constitutional norms. In this context, the understanding of the autonomy of will goes through the examination of the article 5, II of the Federal Constitution. Thus, autonomy of will constitutes the power that a person has to establish certain legal business with someone aiming to set up a private legal relationship. The article also discusses autonomy of will and private autonomy, establishing possible differences and similitudes. It concludes that the institute of autonomy of will is placed in the context of Civil Law and its use, by the person, in the execution of private legal transactions must comply with constitutional principles.

Keywords: Fundamental rights. Autonomy of will. Private autonomy. Human Dignity. 
SumÁRIo: Introdução. 1. A Constituição Federal de 1988 e o princípio da dignidade humana. 2. Breves relatos sobre o código civil brasileiro frente à constitucionalização. 3. Autonomia da vontade ou autonomia privada. Conclusão. Referências.

\section{INTRODUÇÃO}

Pretende-se, com o presente artigo, apresentar breves considerações sobre o instituto da autonomia da vontade, a partir da análise do texto constitucional e do Código Civil.

Utilizando-se a prática dedutiva, o trabalho está dividido em três partes. Inicia-se com o exame da Constituição da República Federativa do Brasil de 1988, quando será verificada a inserção da pessoa, em seu contexto, a partir do momento histórico em que foi promulgada, com as implicações legais produzidas, em virtude do envolvimento dos princípios nos quais está fundamentada, considerando especialmente o princípio da dignidade humana.

Em segundo plano, haverá a necessidade de se perquirir, no Código Civil, os efeitos do texto constitucional, tendo em vista que a legislação infraconstitucional deve obediência à Constituição Federal, bem como o contexto no qual o Código Civil atual foi desenvolvido.

Na sequência, será retratado o instituto da autonomia da vontade, a partir de sua contextualização constitucional e no Direito Civil para, com substratos teóricos, buscar um entendimento mínimo de sua natureza jurídica.

Objetiva-se, com o estudo específico, averiguar a ligação, os sistemas, onde se situa, em que contexto e quando a autonomia da vontade pode ser utilizada pelo indivíduo.

\section{A Constituição Federal de 1988 e o princípio da dignidade humana}

A Constituição da República Federativa do Brasil relaciona extenso rol de direitos às pessoas ${ }^{139}$, com presença constante em suas vidas, por conta das inúmeras e variadas mudanças sociais, com o Direito, e obrigatoriamente acompanhando as alterações que se operam no seio da sociedade.

De acordo com o sistema normativo brasileiro, a Carta Magna é o seu ápice, ou seja, todo o ordenamento jurídico subalterno lhe deve obediência. A inob-

${ }^{139}$ Conforme Título II - Dos Direitos e Garantias Fundamentais, Capítulo I - Dos Direitos e Deveres Individuais e Coletivos: art. $5^{\circ}$, caput, seus 78 incisos e 4 parágrafos, da Constituição Federal. 
servância a seus preceitos produz a inconstitucionalidade da norma, o que inviabiliza a aplicação e a validade da norma dita inconstitucional.

Os princípios fundamentais da Constituição Federal, mencionados em seu art. $1^{140}$, dão o tom não só ao texto constitucional, como ao restante da legislação infraconstitucional. Uma atenção especial deve ser conferida ao princípio da dignidade da pessoa humana, haja vista constatar-se que no Brasil deve vigorar sob um Estado Democrático de Direito.

O marco legal produzido pela promulgação da Constituição Federal inaugurou não só um novo momento do sistema legal brasileiro, mas também permitiu a transição política de um estado autoritário, proveniente da época do regime da ditadura militar, para um regime dito democrático, atualmente com pouco mais de 25 (vinte e cinco) anos de existência.

Obviamente que o denominado Estado Democrático de Direito, no qual vigora o império da lei, trouxe inúmeras transformações ao cidadão brasileiro. Os direitos e garantias individuais foram restabelecidos, sob nova roupagem constitucional e política, o que nos interessa sobremaneira no presente estudo, especialmente no que diz respeito à autonomia da vontade.

A Constituição trouxe à tona o verdadeiro sentido do ordenamento jurídico: a proteção à pessoa, ao indivíduo, por intermédio dos direitos da personalidade, em diversos aspectos, o que se confirma nas palavras de Gustavo Tepedino ${ }^{141}$ (2008, p. 53): "Assim é que, no caso brasileiro, em respeito ao texto constitucional, parece

${ }^{140}$ Art. $1^{\circ}$. A República Federativa do Brasil, formada pela união indissolúvel dos Estados e Municípios e do Distrito Federal, constitui-se em Estado Democrático de Direito e tem como fundamentos:

I - a soberania;

II - a cidadania;

III - a dignidade da pessoa humana;

IV - os valores sociais do trabalho e da livre iniciativa;

V - o pluralismo político.

Parágrafo único. Todo o poder emana do povo, que o exerce por meio de representantes eleitos ou diretamente, nos termos desta Constituição.

${ }^{141}$ TEPEDINO, Gustavo. Temas de Direito Civil. 4.ed. rev. e atual. Rio de Janeiro: Renovar, 2008. Prossegue o autor (p. 53): "Nesta direção não se trataria de enunciar um único direito subjetivo ou classificar múltiplos direitos da personalidade, senão, mas tecnicamente, de salvaguardar a pessoa humana em qualquer momento da atividade econômica, quer mediante os específicos direitos subjetivos (previstos pela Constituição e pelo legislador especial saúde, imagem, nome, etc.), quer como inibidor de tutela jurídica de qualquer ato jurídico patrimonial ou extrapatrimonial que não atenda à realização da personalidade. A prioridade conferida à cidadania e à dignidade da pessoa humana (art. $1^{\circ}$, I e III, CF), fundamentos da República, e a adoção do princípio da igualdade substancial (art. $3^{\circ}$, III), ao lado da isonomia formal do art. $5^{\circ}$, bem como a garantia residual estipulada pelo art. $5^{\circ}, \S 2^{\circ}, \mathrm{CF}$, condicionam o intérprete e o legislador ordinário, modelando todo o tecido normativo infraconstitucional com a tábua axiológica eleita pelo constituinte." 
lícito considerar a personalidade não como um novo reduto de poder do indivíduo, no âmbito do qual seria exercido a sua titularidade, mas como valor máximo do ordenamento, modelador da autonomia privada, capaz de submeter toda a atividade econômica a novos critérios de validade."

Adiante, ao tratar das relações jurídicas privadas e direitos humanos, Gustavo Tepedino ${ }^{142}(2008$, p. 64) faz um pequeno, mas importante, resgate histórico da necessidade da proteção à pessoa, especialmente pela manutenção de sua base no direito público, que não respondia mais à altura do desenvolvimento social em progressão, que precisa ser trazido à colação: "Vale dizer, a estrutura dogmática que dominou as grandes codificações européias do século XIX, e gizou as linhas mestras do sistema jurídico pátrio, baseia-se na summa diviso herdada do direito romano, que extrema o direito público e o direito privado. Inspirado pelas idéias jusnaturalistas que exaltavam o indivíduo, o direito civil assegurava a liberdade de contratar e a franca apropriação dos bens, ao passo que a doutrina dos direitos humanos, concebida a partir do século passado, engendrou mecanismos de proteção do indivíduo em face do Estado. Cuida-se, pois, de duas faces da mesma moeda. A sublimação do indivíduo no direito civil dá-se pela autonomia da vontade, enquanto as garantias fundamentais, concebidas pelo direito público, afastam as ingerências do Estado da esfera privada."

Tratando-se a respeito da melhoria das condições da classe trabalhadora pobre, surgida em decorrência dos desdobramentos da Revolução Industrial, no final do século XIX, Andreza Cristina Baggio Torres ${ }^{143}$ (2006, p. 54) ressalta os desdobra-

${ }^{142}$ Ob. cit. p. 64. Prossegue o autor: "Eis as linhas mestras que, perfeitamente compatíveis com as necessidades da sociedade pré-industrial, mostram-se, no entanto, abaladas pela crescente demanda da sociedade tecnológica, onde a economia massificada e os avanços científicos perturbam a demarcação antes cristalina dos territórios do direito público e do direito privado. O dirigismo contratual e a formulação de novos meios - processuais e substanciais - de controle e de participação social corroboram este fenômeno de superposição dos espaços público e privado, suscitando uma redefinição de limites e uma profunda relativização conceitual. Na democracia capitalista globalizada, de pouca serventia mostram-se os refinados instrumentos de proteção dos direitos humanos, postos à disposição pelo direito público, se as políticas públicas e a atividade econômica privada escaparem aos mecanismos de controle jurídico, incrementando a exclusão social e o desrespeito à dignidade humana. Na era dos contratos de massa e na sociedade tecnológica, pouco eficazes mostram-se os mecanismos tradicionalmente empregados pelo direito civil, como a responsabilidade civil fundada na culpa, sendo indiscutíveis os riscos sociais decorrentes da atividade econômica, mais e mais sofisticada, impondo-se a busca de soluções de índole objetiva, preferencialmente preventivas, não meramente ressarcitórias, em defesa de uma melhor qualidade de vida e da realização da personalidade."

${ }^{143}$ TORRES, Andreza Cristina Baggio. Direito Civil-Constitucional: a função social do contato e a boa-fé objetiva como limites à autonomia privada. In: NALIN, Paulo Roberto Ribeiro (Org.). Contrato \& Sociedade: a autonomia privada na legalidade constitucional. Curitiba: Juruá, 2006. v.2. pp. 47-79. E a autora prossegue (p. 55): "Nessa linha de pensamento, os 
mentos das duas Grandes Guerras Mundiais referentes à intervenção estatal nos domínios privados, pois a partir da Primeira Guerra Mundial, com a economia desenvolvida e a população num crescente, a legislação da época não era mais suficiente para atender ao mercado, considerando-se, especialmente, um aumento das relações de consumo. Com a Constituição mexicana de 1917 e também com a Constituição de Weimar, de 1919, nasce o Estado Social, que passa a ter ingerência direta nas relações entre particulares, a fim de minimizar as desigualdades sociais e proporcionar bem-estar a todos, possibilitando o acesso aos bens de consumo. A partir de então, o Estado Social prevê a proteção de direitos, notadamente aquele referente à vida e à dignidade. Após a Segunda Guerra Mundial, firmou-se na maioria dos Estados a ideia de que o bem-estar de todos estaria diretamente relacionado à intervenção do Estado e não somente àqueles que possuíam algum poder econômico.

A partir da tendência desenhada de alteração para o viés da vida do indivíduo como um todo, no contexto da satisfação de seus legítimos interesses e de acordo com as peculiaridades locais, verifica-se que a Constituição da República Federativa do Brasil de 1988, que inaugurou um novo tempo na política do País, alterou sensivelmente o ordenamento jurídico, haja vista que privilegiou a vida e a dignidade humana, valorizando a realização humana e abandonando o individualismo exagerado.

Também mencionando o Estado Social antes, com suas consequências, e o Estado Liberal depois, com sua oposição aos sistemas pretéritos, Beatriz França ${ }^{144}$

direitos humanos tomam corpo, e as necessidade do homem, enquanto ser que merece ter protegida sua própria vida, passa a ser objeto de preocupação maior do Estado, em detrimento das simples relações particulares de circulação de riquezas, as quais normalmente estavam, como até hoje ainda estão, nas mãos de poucos." Seu arremate caracteriza o ser humano como objeto do sistema legal, renegando a segundo plano a visão patrimonialista (p. 57): “A proteção constitucional ao homem, na qualidade de ser humano que merece se dignamente respeitado, hoje guarda posição de centralidade dentro do ordenamento jurídico civil, em detrimento da clausura patrimonial de outrora. Sujeito capaz não é mais somente aquele que pode constituir família, adquirir patrimônio, mas aquele que possui direito à satisfação de necessidade mínimas de subsistência e sobrevivência."

${ }^{144}$ FRANÇA, Beatriz. A (des)construção do direito privado em face da despatrimonialização do sujeito de direito civil constitucional - aspectos constitucionais da autonomia privada. In: NALIN, Paulo Roberto Ribeiro (Org.). Contrato \& Sociedade: a autonomia privada na legalidade constitucional. Curitiba: Juruá, 2006. v.2. p. 81-102. Na sequência, a autora adverte (p. 97): "As mudanças constitucionais se refletiram no enfoque dado aos princípios e valores que formavam a base da família, do direito à propriedade, da liberdade negocial, entre outros. Tudo leva a crer que, antes da Constituição Federal, o Código Civil tinha o subversivo poder de atuar como uma Constituição da Vida Privada, contudo, hoje ele se submete à obediência de cláusulas gerais guardadas pela Constituição. Os valores trazidos pela Constituição provocaram mudanças até na ótica civilista, pois, até então, o Direito Civil considerado matéria de caráter exclusivo do Direito Privado, passou a sofrer notória intervenção do Direito Público. Após o processo de constitucionalização do Direito Civil, iniciou-se a despatrimonialização 
(2006, p. 93) relata o nascimento do dirigismo contratual, com a imposição de limites à autonomia privada, à propriedade, bem como ao controle de bens. Concomitantemente, houve o desenvolvimento de programas assistenciais, comprovando que o individualismo "naufragara".

Eros Belin de Moura Cordeiro ${ }^{145}$ (2009, p. 223), a partir da concentração de capital e da massificação da sociedade, fenômenos do século XX determinantes à caracterização da fragilidade do ser humano, alerta que "o sujeito do direito civil clássico cede espaço para a pessoa, centro do direito civil contemporâneo. Tal ordem de ideias, cujos vetores centrais são a pessoa humana e a solidariedade social, é que foram cristalizadas na ordem constitucional brasileira inaugurada em 1988." A Constituição Federal, centrada no ser humano e tendo como um dos princípios norteadores a dignidade da pessoa humana, revitalizou o ordenamento jurídico pátrio, no sentido da preservação do indivíduo e privilegiando a pessoa, irradiando estas diretivas para todo o sistema, que lhe deve satisfação. Na sequência, verificam-se alguns acontecimentos atinentes ao Código Civil brasileiro.

\section{BreVes RElatos SObre O Código CIVIL BRASILEIRO FRENTE À CONSTITUCiO- NALIZAÇÃO}

Esclarecidas questões acerca da ordem constitucional, a referência ao Direito Civil é obrigatória para melhor entendimento do que aqui se propõe. $\mathrm{O}$ atual Código - Lei n. 10.406, de 10 de janeiro de 2002, vigora desde 11 de janeiro de 2003, tendo em vista a vacacio legis de um ano, conforme disposição de seu art. $2.044^{146}$. Houve a revogação do Código Civil anterior - Lei n. 3071, de $1^{\circ}$ de janeiro de 1916, bem como a Parte Primeira do Código Comercial - Lei n. 556, de 25 de junho de 1850, segundo seu art. $2045^{147}$.

Hierarquicamente inferior, o Código Civil (Lei Ordinária Federal), deve estar adequado às determinações do texto constitucional e à interpretação do Código Civil, que segundo Paulo Luiz Netto Lôbo ${ }^{148}$ (2003, p. 198), mudou de forma

da pessoa, para que se valorizasse sua personalização. A Constituição reconheceu a igualdade substancial, pois o Direito Público supriria as necessidades e desigualdades entre os homens em suas relações privadas. Assim, o respeito absoluto à propriedade privada não poderia preponderar sobre a dignidade humana, bem como o homem passava a ser considerado hipossuficiente em diversas relações jurídicas."

${ }^{145}$ CORDEIRO, Eros Belin de Moura. A Constituição da República de 1988 e as transformações na teoria contratual. In: CONRADO, Marcelo; PINHEIRO, Rosalice Fidalgo. Direito Privado e Constituição: ensaios para uma recomposição valorativa da pessoa e do patrimônio. Curitiba: Juruá, 2009. pp. 211-38.

146 Art. 2044. Este Código entrará em vigor um ano após a sua publicação.

${ }^{147}$ Art. 2045. Revogam-se a Lei n. 3071, de $1^{\circ}$ de janeiro de 1916 - Código Civil e a Parte Primeira do Código Comercial, Lei n. 556, de 25 de junho de 1850.

${ }^{148}$ LÔBO, Paulo Luiz Netto. Constitucionalização do Direito Civil. In: NAVES, Bruno Tor- 
substancial, pois deve ocorrer segundo a Constituição e não a Constituição segundo o Código Civil, como ocorria em tempos pretéritos, além do que, deve “... repor a pessoa humana no centro do direito civil, passando o patrimônio ao papel de coadjuvante, nem sempre necessário."

Importante menção histórica é relembrada por Paulo Nalin ${ }^{149}$ (2006, p. 18), quando faz referência à anterioridade da atual codificação à Constituição, pois a Comissão redatora fora constituída em 1969 e apresentado o Projeto de Lei 634 em 1975, quando se tornou a Lei 10.406 somente em 2002, além de ressaltar os quatro marcos científico-axiológicos de posicionamento do Direito Civil nacional.

Paulo Neves $\operatorname{Soto}^{150}$ (2002, p. 264), ao fazer referência ao "novo" Código Civil, com adjetivos interessantes, ressalta a necessidade de adequação do Projeto de 1975 ao texto constitucional: "Quanto à constitucionalidade dos dispositivos do novo Código Civil, pode-se entender que se faz necessária uma interpretação

quato de Oliveira; FIUZA, César; SÁ, Maria de Fátima Freire de (Coords.). Direito Civil: atualidades. Belo Horizonte: Del Rey, 2003. p. 197-217. O autor prossegue (p. 198), mencionando a necessidade de "não apenas investigar a inserção do direito civil na Constituição jurídico-positiva, mas os fundamentos de sua validade jurídica, que dela devem ser extraídos." ${ }^{149}$ NALIN, Paulo. A autonomia privada na legalidade constitucional. In: NALIN, Paulo Roberto Ribeiro (Org.). Contrato \& Sociedade: a autonomia privada na legalidade constitucional. Curitiba: Juruá, 2006. v.2. p. 13-45. São eles: “i) o processo codificador do século XIX, sistematicamente iniciado em 1845, por iniciativa da Constituição de 1824 , à luz do seu art. 179, XVIII ("organizar-se-á, quanto antes, um Código Civil e um Criminal, fundados nas sólidas bases da justiça e da equidade"), culminando com o Código de 1916, tendo sido elaborado por Clóvis Bevilaqua, com o emprego dos projetos e estudos anteriores, entre abril e outubro de 1899; ii) o movimento de recodificação sempre se ateve à experiência codificadora europeia, decorrente do Código Francês de 1804, passando pelo BGB (1900), pelos Códigos Italianos de 1865 e 1942, sem embargo da influente presença lusitana dos Códigos Civis de 1867, 1966 e da atualização desta última, levada a efeito pelo Dec.-lei 496, de 1977); iii) a Constituição Brasileira de 1988, na medida em que estabeleceu o novo sentido do indivíduo, vale dizer, da pessoa e da repersonalização, para tanto, fazendo inserir em seu texto vários dos institutos fundamentais do Direito Civil; iv) o Código Civil brasileiro de 2002, sem embargo de uma análise crítica acerca da adequação do modelo codificador para o atual século XXI."

150 SOTO, Paulo Neves. Novos perfis do direito contratual. In: RAMOS, Carmem Lúcia Silveira; TEPEDINO, Gustavo; BARBOZA, Heloisa Helena; GEDIEL, José Antônio Peres; FACHIN, Luiz Edson; MORAES, Maria Celina Bodin de (Orgs.). Diálogos sobre Direito Civil: construindo uma racionalidade contemporânea. Rio de Janeiro: Renovar, 2002. p. 24765. O autor, contudo, alerta (p. 263): "Em conclusão, podemos dizer que o novo Código Civil não é realmente 'novo' em seu conteúdo, pois apenas confirma as tendências e opções já consideradas pela doutrina e jurisprudência nacional ao longo das duas últimas décadas, porém, ao adotar expressamente os princípios do novo Direito Contratual, põe fim à resistência, tacanha, aos novos paradigmas do Direito Privado, promovida pelos operadores do direito que insistiam na defesa do princípio da autonomia da vontade. Na sua conformação oitocentista garante o novo código a mudança de forma expressa 'na letra fria da lei'."

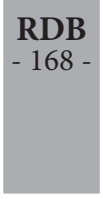


conforme a Constituição para se determinar o correto conteúdo que deve ter a lei ou 'Constituição do direito privado' ou 'do homem comum', adequando a nova lei aos princípios maiores da Constituição da República Federativa do Brasil de 1988, aparando 'arestas' preenchendo lacunas e atualizando a lógica do projeto de 1975 ao pacto social de 1988."

Em que pese o projeto do Código Civil de 2002 (em vigor desde 2003) ser de 1975, a Constituição Federal é de 1988, ou seja, cronologicamente inserida entre o projeto, que comportou cerca de 37 (trinta e sete) anos de trâmite parlamentar e sua efetiva aplicação e vigência.

Apesar do lapso temporal, sob o aspecto jurídico-legal, não ser demasiado, implica em algumas diferenças comportamentais, sociais e morais, pois o que era em 1975, pode não ser em 1988 e comportar uma terceira via em 2003 (considerando, ainda, que estamos em 2014). Ora, como já sustentado, o Código Civil, mesmo posterior à Constituição Federal, lhe deve obrigação hierárquica e, portanto, precisa obedecer aos seus preceitos.

Ao que parece, considerando que a Constituição da República produz normas jurídicas, posto que dotada de juridicidade, seus efeitos se propagam ao restante do ordenamento jurídico do qual é o maior expoente. Trata-se da constitucionalização do Direito Civil, que para Luís Roberto Barroso ${ }^{151}$ (2005, p. 53) implica na “(...) irradiação dos valores abrigados nos princípios e regras da Constituição por todo o ordenamento jurídico, notadamente por via da jurisdição constitucional, em seus diferentes níveis."

Também acerca do fenômeno da "constitucionalização do direito", após inúmeras considerações teóricas, especialmente quanto ao (novo) Código Civil e à intervenção por parte do Estado em diversos ramos do direito privado, com alterações na técnica legislativa, Gustavo Tepedino ${ }^{152}$ (2003, p. 127), dedica atenção à matéria: "Constitucionalização do direito civil, em uma palavra, não é apenas um

${ }^{151}$ BARROSO, Luís Roberto. Neoconstitucionalismo e Constitucionalização do Direito (o triunfo tardio do Direito Constitucional no Brasil). In: Interesse Público. Porto Alegre: Notadez, 33(7)13-54, set/out 2005. Prossegue o autor (p. 53): "Dela resulta a aplicabilidade direta da Constituição a diversas situações e, sobretudo, a interpretação das normas infraconstitucionais conforme a Constituição, circunstância que irá conformar-lhes o sentido e o alcance." Também são discutidos, no mesmo estudo, outros aspectos da constitucionalização do Direito, especialmente no Direito Civil, com incursões no Direito Administrativo e no Direito Penal, bem como a judicialização das relações sociais. Importante ressaltar que, quanto à constitucionalização do Direito Civil, dois daqueles aspectos são especialmente ressaltados pelo Autor: o princípio da dignidade da pessoa humana e a aplicabilidade dos direitos fundamentais às relações privadas.

152 TEPEDINO, Gustavo. A constitucionalização do direito civil: perspectivas interpretativas diante do novo código. In: NAVES, Bruno Torquato de Oliveira; FIUZA, César; SÁ, Maria de Fátima Freire de (Coords.). Direito Civil: atualidades. Belo Horizonte: Del Rey, 2003. pp. $115-30$. 
adjetivo a colorir a dogmática forjada pela Escola da Exegese, que pode ser cada momento purificada ou atualizada, mas uma alteração profunda da ordem pública, a partir da substituição dos valores que permeiam o direito civil, no âmbito do qual a pessoa humana passa a ter prioridade absoluta."

Reafirma, adiante, a proteção à pessoa humana, porquanto a Constituição Federal de 1988 seria ${ }^{153}$ “... responsável pela transformação valorativa do direito civil, elegendo a dignidade da pessoa humana como valor central do ordenamento, ao qual funcionalizou as relações jurídicas patrimoniais. Suplantou, com isso, todas as formulações conceitualistas que idealizavam o direito civil como estatuto das relações patrimoniais." Apesar do avanço constitucional, Gustavo Tepedino ${ }^{154}$ qualifica o novo Código como retrógado, demagógico e obsoleto, considerando que "... mais de 2000 artigos do novo diploma, retratam o descompasso entre o texto aprovado e a realidade social."

Ainda sobre o tema "constitucionalização do direito civil", Fernando José Breda Pessôa ${ }^{155}$ (2006, p. 111), ao relacionar a passagem do século XX para o século XXI, especificamente no campo do Direito Privado, assinala que "(...) todos os câ-

${ }^{153}$ Ob. cit. p. 128.

${ }^{154}$ Ob. cit. ps. 128 e 130. O Autor continua tecendo críticas ao Código Civil: "O novo Código nasce velho principalmente por não levar em conta a história constitucional brasileira e a corajosa experiência jurisprudencial, que protegem a personalidade humana mais do que a propriedade, o ser mais do que o ter, os valores existenciais mais do que os patrimoniais. E é demagógico porque, engenheiro de obras feitas, pretende consagrar direitos que, na verdade, estão tutelados em nossa cultura jurídica pelos menos desde o pacto político de outubro de 1988. Ressalte-se ainda que, também do ponto de vista técnico, o Código já surge obsoleto. Alguns exemplos: os direitos da personalidade foram regulados de maneira tímida e tipificadora, nos arts. 11 a 21, seguindo doutrina que teve os seus dias de glória nos anos 60, desconhecedora da cláusula geral de proteção da pessoa humana que viria a ser corporificada na Lei Maior."

${ }^{155}$ PESSÔA, Fernando José Breda. Contratos, autonomia da vontade e perspectiva comunitária. In: NALIN, Paulo Roberto Ribeiro (Org.). Contrato \& Sociedade: a autonomia privada na legalidade constitucional. Curitiba: Juruá, 2006. v.2. p. 103-29. As referências legais posteriores, bem como a alusão ao direito contratual, utilizadas pelo autor (p. 112), são pertinentes: "Porém, é justamente no direito contratual que o processo de constitucionalização é mais lentamente implementado dentro da esfera privada, por ser ele contrato, o meio essencial de circulação de riquezas, diferentemente, por exemplo, do Direito de Família, em que a modificação de perspectiva é mais facilmente produzida. Em que pese a lentidão, já possui o ordenamento jurídico brasileiro claros exemplos de constitucionalização do Direito Privado. O advento da Lei 8.078/91, mais popularmente conhecida como Código de Defesa do Consumidor, e que se constitui no primeiro texto legislativo de grande relevância a ser produzido sob o comando da ordem constitucional de 1988, já se mostrava impulsionado pelos ventos da constitucionalização. Da mesma sorte seguiu o novo Código Civil aprovado em 2002, que, mediante a utilização do arquétipo das cláusulas gerais, também trabalha sob uma lógica instrumental para o preenchimento e conseqüente implementação de valores constitucionais nas relações jurídicas privadas.”

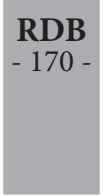


nones tradicionais que caracterizaram as relações interprivadas ao longo dos tempos devem ser condicionadas sob uma perspectiva de realização dos valores constitucionalmente consagrados. Este processo guarda seu principal mérito por, principalmente retirar do centro das relações contratuais o patrimônio (propriedade privada) e o substituir nessa condição de destaque o homem (princípio da dignidade da pessoa humana)."

Pietro Perlingieri ${ }^{156}$ (2007, p. 33), acerca das transformações produzidas no aspecto jurídico, faz uso de uma terminologia um pouco diversa, taxando de "não elegante" o termo "despatrimonialização", mas com objetivo similar, ou seja, o desenvolvimento da pessoa, evidenciando uma opção entre personalismo e patrimonialismo, mas sem expurgar o conteúdo patrimonial do sistema jurídico, especialmente no direito civil, relembrando a importância do aspecto econômico na realidade social, no sentido de "atribuir-lhe uma justificada institucional de suporte ao livre desenvolvimento da pessoa."

Identificadas algumas questões históricas que nortearam a construção do Código Civil em vigor, inclusive a forçosa influência constitucional nos negócios jurídicos privados, é necessário entender do que se trata a autonomia privada, a partir do contexto constitucional-civil.

\section{Autonomia da vontade ou aUtonomia PRIVAda}

A Constituição da República Federativa do Brasil, a partir de seus arts. $1^{\mathrm{o} 157}$, IV, e $170^{158}$, consagra a livre iniciativa, especialmente quando é prevista a li-

${ }^{156}$ PERLINGIERI, Pietro. Perfis do Direito Civil: Introdução do Direito Civil Constitucional. Trad. Maria Cristina de Cicco. 3.ed. Rio de Janeiro: Renovar, 2002.0 autor prossegue (p. 34): "Não é suficiente, portanto, insistir na afirmação da importância dos 'interesses da personalidade no direito privado'; é preciso predispor-se a reconstruir o Direito Civil não com uma redução ou um aumento de tutela das situações patrimoniais, mas com uma tutela qualitativamente diversa. Desse modo, evitar-se-ia comprimir o livre e digno desenvolvimento da pessoa mediante esquemas inadequados e superados; permitir-se-ia o funcionamento de um sistema econômico misto, privado e público, inclinado a produzir modernamente e a distribuir com mais justiça. O pluralismo econômico assume o papel de garantia do pluralismo também político e do respeito à dignidade humana."

${ }^{157}$ Art. $1^{\circ}$. A República Federativa do Brasil, formada pela união indissolúvel dos Estados e Municípios e do Distrito Federal, constitui-se em Estado Democrático de Direito e tem como fundamentos:IV - os valores sociais do trabalho e da livre iniciativa;

${ }^{158}$ Art. 170. A ordem econômica, fundada na valorização do trabalho humano e na livre iniciativa, tem por fim assegurar a todos existência digna, conforme os ditames da justiça social, observados os seguintes princípios:

I - soberania nacional;

II - propriedade privada;

III - função social da propriedade;

IV - livre concorrência; 
berdade contratual, além do que o já mencionado no art. $5^{0159}$, II, do mesmo diploma legal, serve como um dos fundamentos constitucionais da autonomia da vontade no ordenamento jurídico brasileiro.

A autonomia, condicionada ao voluntarismo jurídico e proveniente do liberalismo econômico, a partir de um sucinto recorte histórico, é mencionada por Cristhian Magnus De Marco $^{160}$ (2011, p. 246) e tem papel relevante, considerando sua utilização a partir de F. Gény, em 1899, quando a ideia absoluta de autonomia foi rechaçada pelos ideais socializantes da época. Exigia-se uma forte intervenção estatal, para equilíbrio das relações sociais. Na perspectiva contemporânea, com valores morais e econômicos invertidos, a preservação do Estado do bem-estar social e o convício entre os indivíduos prescinde de uma intervenção estatal contundente, diminuindo o papel da vontade.

A autonomia da vontade, poder este que a pessoa tem de estabelecer determinado negócio jurídico com alguém, objetiva a constituição de uma relação jurídica privada que atenda a uma necessidade pontual, com a observância de certos preceitos legais. Ao Estado, não cabe obstar as referidas práticas negociais, mas proporcionar que as pessoas exerçam seu direito ao exercício da autonomia da vontade, com a

$\mathrm{V}$ - defesa do consumidor;

VI - defesa do meio ambiente;

VI - defesa do meio ambiente, inclusive mediante tratamento diferenciado conforme o impacto ambiental dos produtos e serviços e de seus processos de elaboração e prestação;

VII - redução das desigualdades regionais e sociais;

VIII - busca do pleno emprego;

IX - tratamento favorecido para as empresas de pequeno porte constituídas sob as leis brasileiras e que tenham sua sede e administração no País.

Parágrafo único. É assegurado a todos o livre exercício de qualquer atividade econômica, independentemente de autorização de órgãos públicos, salvo nos casos previstos em lei.

159 No presente estudo, a tônica é a autonomia da vontade da pessoa natural, por conta da sua diferença para com a pessoa jurídica, já que, em situações determinadas, têm tratamento também distinto.

${ }^{160}$ DE MARCO, Cristhian Magnus. Elementos sobre a autonomia privada e sua relação com o mínimo existencial na teoria dos direitos fundamentais. In: BAEZ, Narciso Leandro Xavier Baez; CASSEL, Douglas (Orgs.). A realização e a proteção internacional dos Direitos Humanos: desafios do século XXI. Joaçaba: Ed. UNOESC, 2011. p. 246-59. O autor faz menção importante à vontade (p. 247): "Modernamente está descartada a vontade como gênese das relações jurídicas. Hoje, o que interessa são os 'efeitos produzidos pela ação humana', mais do que a sua causa. A expressão mais atualizada é Autonomia privada, que está a designar: um fato objetivo - 'o poder, reconhecido pela ordenamento jurídico aos particulares, e nos limites traçados pela ordem jurídica, de autorregular os seus interesses, estabelecendo certos efeitos aos negócios que pactuam'; a fonte negocial que deriva direitos e obrigações, e, principalmente, normas criadas pela autonomia privada, e conteúdo próprio, mas limitadas (quanto ao conteúdo ou efeitos) pelo poder estatal em ceras matérias ou relações reservadas à regulação do Estado." 
criação de mecanismos para evitar abusos e injustiças.

Ao mencionar os denominados "atos de autonomia privada", Gerson Luiz Carlos $\operatorname{Branco}^{161}$ (2011, p. 234) os vincula à competência para a nomogênese, que se traduz no poder que o particular possui, partindo de um ato volitivo livre, de criar um negócio jurídico eficaz, obrigatório, vinculando sua conduta em relação a si mesmo e também a terceiros.

Em outro momento, o mesmo autor ${ }^{162}(2011$, p. 237$)$ relaciona liberdade à Constituição com autodeterminação, pois “... a liberdade enquanto permissão constitucional de que os particulares decidam como exercer ou não os direitos inerentes à personalidade é a expressão da autodeterminação (...)."

George Marmelstein ${ }^{163}$ (2013, p. 101), também fazendo referência ao art. $5^{\circ}$, da Constituição Federal, entende a autonomia da vontade "(...) como a faculdade que o indivíduo possui para tomar decisões na sua esfera particular de acordo com

${ }^{161}$ BRANCO, Gerson Luiz Carlos. Autodeterminação e limitação negocial aos direitos da personalidade. In: BAEZ, Narciso Leandro Xavier Baez; CASSEL, Douglas (Orgs.). A realização e a proteção internacional dos Direitos Humanos: desafios do século XXI. Joaçaba: Ed. UNOESC, 2011. pp. 227-44. Para o autor (pg. 235): “A doutrina brasileira considera que o sistema constitucional brasileiro pressupõe a autonomia privada a partir de uma série de comandos que devem ser compreendidos em conjunto, entre eles o artigo $5^{\circ}$, I, XIII, XVII e XXXVI, que tratam da liberdade geral, liberdade profissional, liberdade de associação, e que garantem eficácia ao ato jurídico perfeito e, portanto, a eficácia obrigatória e a irretratabilidade dos contratos. Sob outro ponto de vista, pode-se tomar a concepção de Ana Prata, para quem não se pode considerar a autonomia privada como manifestação da liberdade individual, porque isso representa "erigir em ordem natural aquilo que é ordem económica históricamente referenciada", razão pela qual parte da doutrina considera que a liberdade contratual repousa mais no art. 170 da Constituição Federal, na disciplina da ordem econômica, do que nas disposições do art. $5^{\circ}$."

162 Ob. cit. p. 237.

${ }_{163}$ MARMELSTEIN, George. Curso de Direitos Fundamentais. 4.ed. São Paulo: Atlas, 2013. O autor prossegue (p. 18): "Cada um deve ser senhor de si, agindo como um ser responsável por suas próprias escolhas pessoais, especialmente por aquelas que não interferem na liberdade alheia. A proteção da autonomia da vontade tem como objetivo conferir ao indivíduo o direito de autodeterminação, ou seja, de determinar autonomamente o seu próprio destino, fazendo escolhas que digam respeito a sua vida e ao seu desenvolvimento humano, como a decisão de casar-se ou não, de ter filhos ou não, de definir sua orientação sexual etc." O autor, ainda (p. 102), relata que, mesmo a Constituição brasileira, sendo "tão generosa ao proclamar direitos", não há "nenhum dispositivo que consagre claramente o direito à autonomia privada", mas menciona, como "fonte normativa para a proteção da autonomia da vontade, o art. $5^{\circ}$, inc. II." Também há dois relatos, ilustrativos, de decisões proferidas pela Suprema Corte norte-americana: a primeira, de 1965, no caso Griswold vs. Connecticut, na qual "ficou decidido que o Estado não poderia, nem mesmo por lei, proibir a comercialização ou a utilização de anticoncepcionais." A segunda, de 2003, no caso Lawrence vs. Texas, "a Suprema Corte norte-americana anulou uma lei do Texas que punia criminalmente a prática do homossexualismo." 
seus próprios interesses e preferências."

Insta observar, considerando o que já foi dito, se existe semelhança entre autonomia da vontade e autonomia privada. Para Carlos Alberto Mota Pinto ${ }^{164}$ (2005, p. 102), ao discorrer sobre a autonomia privada e liberdade contratual, não existe diferença entre as autonomias - da vontade e privada, pois o negócio jurídico se constitui na “... manifestação do princípio da autonomia privada ou da autonomia da vontade, subjacente a todo o direito privado."

Entretanto, há quem distinga as autonomias - privada e da vontade. Iniciando com a liberdade jurídica, ou seja, a "possibilidade de a pessoa atuar com eficácia jurídica", Francisco Amaral ${ }^{165}$ (2006, p. 345) passa pela autonomia, "esfera de liberdade de que o agente dispõe no âmbito do direito privado, (...) direito de reger-se por suas próprias leis" e termina com a distinção anunciada, já que a autonomia da vontade seria a manifestação da liberdade de cada um dentro do campo jurídico, enquanto que a autonomia privada se constituiria no poder de criar, dentro do âmbito legal, normas jurídicas, ou seja, o poder que uma pessoa tem de atribuir a si mesmo um ordenamento jurídico, complementar ao ordenamento do Estado.

Ao tratar do conceito da autonomia privada, o autor ${ }^{166}$ (2006, p. 345) ainda faz mais uma distinção: "A expressão 'autonomia da vontade' tem uma conotação subjetiva, psicológica, enquanto a autonomia privada marca o poder da vontade no direito de um modo objetivo, concreto e real".

A diferença entre as autonomias - privada e da vontade, também é sinteticamente ressaltada por Érico de Pina $\mathrm{Cabral}^{167}$ (2004, p. 111), para quem a autonomia da vontade está relacionada com a liberdade de autodeterminação enquanto que

${ }^{164}$ PINTO, Carlos Alberto Mota. Teoria Geral do Direito Civil. 4.ed. por António Pinto Monteiro e Paulo Mota Pinto. Coimbra: Coimbra Editora, 2005. O autor esclarece, em nota de rodapé (99), que esfera jurídica entende-se como "o conjunto das relações jurídicas de que uma pessoa é titular" e prossegue: "Mas não é só através do negócio jurídico que a autonomia da vontade ou autonomia privada se revela e actua, embora seja o negócio jurídico o seu meio principal de actuação. A autonomia privada também se manifesta no poder de livre exercício dos seus direitos ou de livre gozo dos seus bens pelos particulares - ou seja, é a autonomia privada que se manifesta na $<<$ soberania do querer $>>$ - no império da vontade - que caracteriza essencialmente o direito subjectivo."

165 AMARAL, Francisco. Direito Civil: introdução. 6.ed. rev. atual. e aum. Rio de Janeiro: Renovar, 2006.

${ }^{166}$ Ob. cit. p. 345.

${ }^{167}$ CABRAL, Érico de Pina. A “autonomia" no direito privado. In: Revista de Direito Privado. São Paulo: Revista dos Tribunais, 19(5)83-129, jul/set 2004. Em momento imediatamente anterior, o autor (p. 84), menciona que: "O vocábulo autonomia vem do grego autos + nomos e significava independência, autodeterminação, o que é regido por leis próprias; direito de reger-se segundo leis próprias, em regime de liberdade e independência; faculdade de determinar as próprias normas de conduta, sem imposições de outrem. Etimologicamente, autonomia significa o poder de modelar por si - e não por imposição externa - as regras da própria conduta. Isto é, autonomia é a capacidade de governar-se com as próprias regras." 
a autonomia privada seria o poder de autoregulamentação.

A autonomia privada, então, se constitui no gênero, enquanto que a autonomia da vontade pode ser a espécie, considerando a autonomia da vontade vinculada à vontade interna (psíquica) e à liberdade de atuação de cada pessoa, com a possibilidade de escolha do tipo de obrigação a que se pretende aderir, enquanto a autonomia privada, por sua vez, tem relação direta com a liberdade de contratação, ou seja, com a criação de normas para si.

Além da diferenciação entre autonomia da vontade e autonomia privada, novamente Gerson Luiz Carlos Branco ${ }^{168}$ (2011, p. 234) menciona a prevalência do termo "autonomia privada", posto que "a partir da metade do século XX o debate em torno da 'autonomia privada' predominou quando o objeto era a discussão a respeito do fenômeno jurídico vinculado à liberdade nos atos da vida privada e da forma de criação das obrigações."

O viés econômico de autonomia privada é ressaltado por Enzo Roppo ${ }^{169}$ (1988, p. 128), quando trata do "princípio da liberdade contratual" como a "vontade concorde das partes, constituindo o ponto de confluência e de equilíbrio entre os interesses - normalmente contrapostos - de que as mesmas são portadoras."

A autonomia da vontade e a autonomia privada, independentemente da diferença e do significado semântico de cada uma delas, se constituem em liberdades fundamentais à disposição da pessoa humana para lhe proporcionar inserção social e realização plena, seja por intermédio da efetivação de negócios jurídicos, seja praticando atos simples, cotidianos, objetivando a preservação da dignidade e de acordo com necessidades pontuais e específicas. A partir de seu âmbito de utilização, a autonomia de cada pessoa deve servir à satisfação de seus desejos e necessidades, desde que não afronte ao direito ou cause prejuízo a outras pessoas, considerando a existência, por igual, da autonomia das outras pessoas, também sujeitos de direitos.

\section{Conclusão}

A promulgação da Constituição da República Federativa do Brasil de 1988 inaugurou um novo momento na história política brasileira, por conta da transição de um estado autoritário, decorrente do regime militar, para um Estado Democrático de Direito. Nessa condição, as alterações provenientes do texto constitucional proporcionaram um extenso rol de direitos e garantias à pessoa humana, enaltecendo o

${ }_{168}$ Ob. cit. p. 237.

169 ROPPO, Enzo. O contrato. Trad. Ana Coimbra e M. Januário C. Gomes. Coimbra: Almedina, 1988. Prossegue o autor, logo adiante: "Em linha de princípio, portanto, os sujeitos privados são livres de obrigar-se como quiserem. Mas quando se obrigam, obrigam-se verdadeiramente; aquilo que livremente escolheram torna-se vínculo rigoroso dos seus comportamentos, e se violam a palavra dada, respondem por isso e sujeitam-se a sanções." Quanto ao "princípio da autonomia privada", para o autor (p. 142), "implica que a vontade das partes deve considerar-se a principal das fontes de determinação do regulamento contratual."

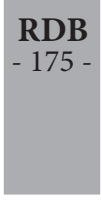


indivíduo, na sua condição de verdadeiro sujeito de direitos, inclusive com reflexos no âmbito do Direito Privado.

O Código Civil atual, em que pese ter o início dos trabalhos de sua construção legislativa ainda no século passado, com longo trâmite parlamentar, por imperativo legal deve obediência à Lei Maior, pois entrou em vigor somente em 2003. Mesmo eminentemente privado, tendo em vista as peculiaridades do Direito Civil, sofreu influência constitucional, também privilegiando a pessoa humana, no seu sentido mais amplo.

Enaltecida a pessoa humana no contexto constitucional-civil, a autonomia da vontade também sofre influência, haja vista que seu caráter quase absoluto de outrora se tornou mais restrito, especialmente pelo princípio constitucional da dignidade da pessoa humana. $\mathrm{O}$ instituto da autonomia da vontade é admitido no ordenamento jurídico brasileiro, como princípio essencialmente de Direito Privado, mas a autonomia da vontade da pessoa existe dentro de nosso sistema jurídico desde que obedecido o plano constitucional-civil.

Há essencial proteção da pessoa e, por conseguinte, de sua autonomia da vontade no Código Civil brasileiro e, na constituição de negócios jurídicos privados, a pessoa que utilizar sua autonomia da vontade deve observar os princípios constitucionais.

\section{REFERÊNCIAS}

AMARAL, Francisco. Direito Civil: introdução. 6.ed. rev. atual. e aum. Rio de Janeiro: Renovar, 2006.

BARROSO, Luís Roberto. Neoconstitucionalismo e Constitucionalização do Direito (o triunfo tardio do Direito Constitucional no Brasil). In: Interesse Público. Porto Alegre: Notadez, 33(7)13-54, set/out 2005.

BRANCO, Gerson Luiz Carlos. Autodeterminação e limitação negocial aos direitos da personalidade. In: BAEZ, Narciso Leandro Xavier Baez; CASSEL, Douglas (Orgs.). A realização e a proteção internacional dos Direitos Humanos: desafios do século XXI. Joaçaba: Ed. UNOESC, 2011. pp. 227-44.

CABRAL, Érico de Pina. A "autonomia" no direito privado. In: Revista de Direito Privado. São Paulo: Revista dos Tribunais, 19(5)83-129, jul/set 2004.

CORDEIRO, Eros Belin de Moura. A Constituição da República de 1988 e as transformações na teoria contratual. In: CONRADO, Marcelo; PINHEIRO, Rosalice Fidalgo. Direito Privado e Constituição: ensaios para uma recomposição valorativa da pessoa e do patrimônio. Curitiba: Juruá, 2009. pp. 211-38.

DE MARCO, Cristhian Magnus. Elementos sobre a autonomia privada e sua relação com o mínimo existencial na teoria dos direitos fundamentais. In: BAEZ, Narciso Leandro Xavier Baez; CASSEL, Douglas (Orgs.). A realização e a proteção inter-

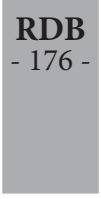


nacional dos Direitos Humanos: desafios do século XXI. Joaçaba: Ed. UNOESC, 2011. pp. 246-59.

FRANÇA, Beatriz. A (des)construção do direito privado em face da despatrimonialização do sujeito de direito civil constitucional - aspectos constitucionais da autonomia privada. In: NALIN, Paulo Roberto Ribeiro(Org.). Contrato \& Sociedade: a autonomia privada na legalidade constitucional. Curitiba: Juruá, 2006. v.2. pp. 81-102.

LÔBO, Paulo Luiz Netto. Constitucionalização do Direito Civil. In: NAVES, Bruno Torquato de Oliveira; FIUZA, César; SÁ, Maria de Fátima Freire de (Coords.). Direito Civil: atualidades. Belo Horizonte: Del Rey, 2003. pp. 197-217.

MARMESLTEIN, George. Curso de Direitos Fundamentais. 4.ed. São Paulo: Atlas, 2013.

NALIN, Paulo Roberto Ribeiro. A autonomia privada na legalidade constitucional. In: NALIN, Paulo Roberto Ribeiro (Org.). Contrato \& Sociedade: a autonomia privada na legalidade constitucional. Curitiba: Juruá, 2006. v.2. pp. 13-45.

PERLINGIERI, Pietro. Perfis do Direito Civil: Introdução do Direito Civil Constitucional. Trad. Maria Cristina de Cicco. 3.ed. Rio de Janeiro: Renovar, 2002.

PESSÔA, Fernando José Breda. Contratos, autonomia da vontade e perspectiva comunitária. In: NALIN, Paulo Roberto Ribeiro (Org.). Contrato \& Sociedade: a autonomia privada na legalidade constitucional. Curitiba: Juruá, 2006. v.2. p. 103-29.

PINTO, Carlos Alberto Mota. Teoria Geral do Direito Civil. 4.ed. por António Pinto Monteiro e Paulo Mota Pinto. Coimbra: Coimbra Editora, 2005.

ROPPO, Enzo. O contrato. Trad. Ana Coimbra e M. Januário C. Gomes. Coimbra: Almedina, 1988.

SOTO, Paulo Neves. Novos perfis do direito contratual. In: RAMOS, Carmem Lúcia Silveira; TEPEDINO, Gustavo; BARBOZA, Heloisa Helena; GEDIEL, José Antônio Peres; FACHIN, Luiz Edson; MORAES, Maria Celina Bodin de (Orgs.). Diálogos sobre Direito Civil: construindo uma racionalidade contemporânea. Rio de Janeiro: Renovar, 2002. pp. 247-65.

TEPEDINO, Gustavo. Temas de Direito Civil. 4. ed. rev. e atual. Rio de Janeiro: Renovar, 2008.

A constitucionalização do direito civil: perspectivas interpretativas diante do novo código. In: NAVES, Bruno Torquato de Oliveira; FIUZA, César; SÁ, Maria de Fátima Freire de (Coords.). Direito Civil: atualidades. Belo Horizonte: Del Rey, 2003. pp. 115-30.

TORRES, Andreza Cristina Baggio. Direito Civil-Constitucional: a função social do contato e a boa-fé objetiva como limites à autonomia privada. In: NALIN, Paulo Roberto Ribeiro (Org.). Contrato \& Sociedade: a autonomia privada na legalidade constitucional. Curitiba: Juruá, 2006. v.2. pp. 47-79. 